\title{
0 objeto, a finalidade e os instrumentos do processo de trabalho em saúde na atenção à violência de gênero em um serviço de atenção básica
}

\author{
Luana Rodrigues de Almeida ${ }^{(a)}$ \\ Ana Tereza Medeiros Cavalcanti da Silva ${ }^{(b)}$ \\ Liliane dos Santos Machado ${ }^{(c)}$
}

Almeida LR, Silva ATMC, Machado LS. The object, the purpose and the instruments of healthcare work processes in attending to gender-based violence in a primary care service. Interface (Botucatu). 2014; 18(48):47-59.

The objective of this study was to analyze professional practices in attending to the health of women in situations of violence, identifying the elements of the work process and their relationship to emancipation from gender oppression. For this, it was investigated among healthcare professionals at a primary care service whether the intentions of the current healthcare policies for women were being implemented within professional practice through work processes designed for this purpose. From a qualitative investigation, the results showed the invisibility of violence in the service and lack of awareness of the gender category and its complexity. Thus, adapting healthcare work processes for attending to women in situations of violence constitutes a major challenge with regard to providing assistance with the potential for emancipation from gender oppression and which is consistent with policy assumptions.

Keywords: Violence against women. Work process. Healthcare personnel.
O objetivo deste estudo foi analisar as práticas profissionais na atenção à saúde da mulher em situação de violência, identificando os elementos do processo de trabalho e sua relação com a emancipação da opressão de gênero. Para tanto, investigou-se, com profissionais de saúde de um serviço de atenção primária, se as intenções da atual política de saúde da mulher estariam sendo realizadas na prática profissional por meio dos processos de trabalho destinados a esse fim. A partir da pesquisa qualitativa, os resultados evidenciaram a invisibilidade da violência no serviço e o desconhecimento da categoria Gênero e da sua complexidade. Configura-se, portanto, a adequação do processo de trabalho em saúde na atenção a mulheres em situação de violência como um grande desafio para a produção de uma assistência potencialmente emancipatória da opressão de gênero e condizente com os pressupostos da política.

Palavras-chave: Violência contra a mulher Processo de trabalho. Pessoal de Saúde.

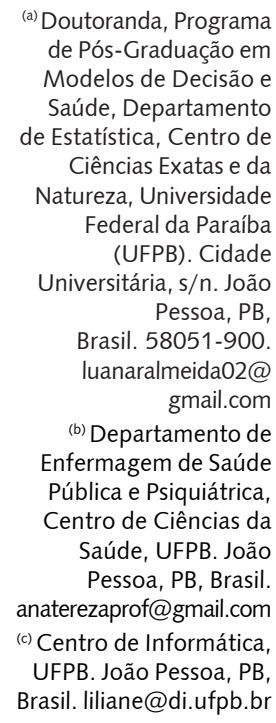

(a) Doutoranda, Programa de Pós-Graduação em Modelos de Decisão e Saúde, Departamento de Estatística, Centro de Ciências Exatas e da Natureza, Universidade Federal da Paraíba (UFPB). Cidade Universitária, s/n. João Pessoa, PB Brasil. 58051-900. luanaralmeida02@ gmail.com

(b) Departamento de Enfermagem de Saúde Pública e Psiquiátrica, Centro de Ciências da Saúde, UFPB. João Pessoa, PB, Brasil. anaterezaprof@gmail.com (c) Centro de Informática, UFPB. João Pessoa, PB Brasil. liliane@di.ufpb.br 


\section{Introdução}

A violência perpetrada contra a mulher é um fenômeno social que tem recebido visibilidade, nos últimos tempos, pela sua elevada frequência, recorrência e severidade dos casos. A magnitude das suas consequências à saúde fez com que o problema fosse reconhecido mundialmente como uma grave questão de Saúde Pública'. Tal violência parece expressar relações de iniquidades entre homens e mulheres nas quais - pela vantagem biológica de sua força física - o homem tem sido beneficiado.

Atualmente, a violência de gênero é reconhecida como uma violação aos direitos humanos das mulheres e é compreendida como a aplicação da força física e/ou constrangimento psicológico que se impõe a alguma mulher contra seus interesses, vontades e desejos ${ }^{2}$. Esse tipo de violência tem sido produzido sob a organização hierárquica do domínio masculino nas relações historicamente delimitadas, culturalmente legitimadas e cultivadas, nas quais a mulher está exposta a agressões objetivas e subjetivas, tanto no espaço público como no privado, com repercussão na sua saúde física e mental .

No sentido de explicar a violência contra a mulher, a categoria sociológica gênero faz uma abordagem que considera a diversidade dos processos de socialização de homens e de mulheres. Contrapõe-se ao entendimento do enfoque hegemônico clássico, que naturalizou as desigualdades entre os sexos, determinando consequências que impactam a vida e as relações dos seres humanos, tanto no plano individual quanto no coletivo, distanciando a mulher de sua emancipação social e trazendo prejuízos para ambos os sexos. Na cultura hegemônica, a rígida divisão sexual da vida social determinou a existência de um mundo masculino cuja base é o poder e o reconhecimento social, enquanto o mundo feminino é relegado à invisibilidade e à falta de valor social ${ }^{4}$. Segundo Fonseca ${ }^{5}$, na atualidade, a contradição de gênero é uma das três grandes contradições produzidas na sociedade ocidental. As outras duas são referentes à classe e à raça/etnia.

A categoria Gênero foi teoricamente reformulada pela historiadora norte-americana Joan Scott. Para Scott ${ }^{6}$, gênero é um termo que se refere aos domínios estruturais e ideológicos existentes na relação entre os sexos, denunciados com veemência pelo movimento feminista, com ênfase no caráter social das distinções baseadas no sexo. Nesse enfoque, o termo gênero indica a "rejeição ao determinismo biológico" e valoriza o aspecto relacional e social da reciprocidade para a compreensão de homens e mulheres ${ }^{6}$.

A violência contra a mulher é hoje reconhecida quase como sinônimo de violência de gênero. Entretanto, Saffioti ${ }^{7}$ defende que a violência de gênero engloba tanto a violência do homem contra a mulher, como o contrário, "uma vez que o conceito de gênero é aberto". Apesar disso, a premissa comum é de que o termo gênero exprime a relação de poder, dominação-exploração, e esse polo explorado é quase predominantemente ocupado pela figura feminina. Por isso, ocorre, comumente, a nomeação da violência contra a mulher como violência de gênero.

Nesse sentido, Guedes et al. ${ }^{8}$ afirmam ser fundamental, para a compreensão da violência conjugal, apoiar-se no enfoque de gênero. Para essas autoras, entender a violência contra a mulher com suporte na abordagem de gênero significa reconhecer a hierarquia de poderes na sociedade, onde a mulher sempre esteve em posição inferior, posição essa aceita e legitimada por desigualdades construídas e naturalizadas ao longo da história.

Considerando a explicação hegemônica sobre a naturalização essencial do feminino e do masculino ou sobre os gêneros naturalizados, a desigualdade sexual, produzida nos primórdios da história, mantém-se na atualidade por meio de interesses sociais igualmente naturalizados, constituindo uma espécie de ideologia que subverte a compreensão da realidade essencial do ser humano e interdita a igualdade no âmbito da diversidade. Segundo Chauí ${ }^{9}$, ao discurso naturalista opõe-se o que afirma que a humanidade do ser humano é construída nas relações sociais. Essa última compreensão pressupõe que os fenômenos sociais sejam produtos da ação humana e possam ser por ela transformados.

No enfoque da construção social como resultado da ação humana, um dos grandes desafios das políticas públicas no Brasil relativas à mulher é transformar a intenção revolucionária da política em gesto que lhe corresponda, na ação de práticas profissionais com potencial para fomentar a emancipação da opressão de gênero. Na área da saúde, isso significa contribuir para o reconhecimento da transformação paradigmática do Modelo de Atenção à Saúde da mulher. A categoria Modelo de Atenção à Saúde é 
compreendida, neste estudo, no enfoque defendido por Gonçalves ${ }^{10}$, como um conceito que tem suporte em três pilares: a) as intenções da política; b) a organização dos serviços, e c) os processos de trabalho. Nesse sentido, defendemos o argumento de que só haverá mudança do modelo de atenção se houver a transformação desses três pilares em um processo dinâmico. No entanto, depois do advento do Sistema Único de Saúde (SUS), verifica-se uma mudança nos dois primeiros eixos, e o que se observa é a manutenção de um processo de trabalho desarticulado com os demais pilares. Disso decorre a importância deste estudo, que analisa os avanços já conquistados nesses três pilares, pela verificação da produção de conhecimentos e de sua aplicação nas práticas profissionais da área da saúde. O estudo também sinaliza sobre a necessidade de produção de novos saberes e práticas, importantes para o reconhecimento de que a área da saúde da mulher apresenta uma lenta aproximação com os princípios e diretrizes emancipatórias que a teoria de gênero defende e o atual sistema de saúde comporta.

$\mathrm{Na}$ especificidade da área da saúde, a mulher apresenta problemas e necessidades singulares, diferentes das necessidades dos demais grupos que compõem a esfera social. Há um reconhecimento oficial sobre o impacto dos determinantes sociais na saúde da mulher, que se manifesta na Política Nacional de Atenção Integral à Saúde da Mulher (PNAISM), ao se afirmar que a vulnerabilidade feminina, frente a certos agravos, está mais relacionada com as questões de gênero, como a situação de discriminação na sociedade, do que com fatores biológicos ${ }^{11}$.

Em trabalhos anteriores de Souza et al. ${ }^{12}$, verificou-se que a discriminação nas relações de trabalho, a sobrecarga pela soma de responsabilidade de trabalho nas esferas pública e doméstica, a violência e a falta de poder de decisão sobre o corpo são exemplos de fatores que provocam ou agravam os problemas de saúde das mulheres. Desse modo, na construção histórica e social das identidades de gênero, tem-se atribuído, às mulheres, condições de vida e trabalho precárias e opressoras (porque subalternas) que impactam sua saúde física, mental e social e, por isso, se requer uma acurada consideração no âmbito da saúde coletiva.

$\mathrm{Na}$ atualidade, um desses fatores de grande destaque é a violência de gênero, fenômeno que passou a fazer parte da agenda da Saúde Pública do Brasil, a partir dos anos de 1990, fundamentalmente pelo crescente número de mortes e traumas que provoca. A Organização PanAmericana da Saúde, em 1994, priorizou a violência social (que contém a violência de gênero) como tema na elaboração do seu plano de ação regional, instando os governos a executarem ações interinstitucionais, a fim de prevenirem as consequências fatais e os agravos à saúde relacionados à violência ${ }^{1}$. O Pacto Nacional pelo Enfrentamento à Violência contra Mulher ${ }^{13}$ reconhece a complexidade e a frequência da violência contra mulher como um problema de saúde pública; e a necessidade de intervenções multidisciplinares não só para o combate, mas, também, para a prevenção, atenção, proteção e garantia dos direitos das mulheres e de sua família em situação de violência, com vistas a superar as desigualdades de gênero.

Nesse contexto, os serviços de saúde fazem parte da rota percorrida por grande parte das mulheres em situação de violência de gênero. Contudo, nesses serviços, segundo Guedes et al. ${ }^{8}$, muitas vezes, a atenção à saúde se restringe à lesão ou ao dano físico, consequência da violência, sem nenhuma, ou muito pouca, consideração sobre ela como categoria sociológica que faz interseção com a área da saúde. Isso porque a lesão se constitui um problema específico da área da saúde, sobretudo no enfoque hegemônico do modelo de assistência tradicional e exclusivamente biológico. No sentido de repensar essas práticas profissionais em saúde, a investigação de programas, serviços, intervenções e tecnologias que analisem o potencial transformador dos instrumentos empregados nos processos de trabalho é um tema a ser levado em conta, por se constituir naquilo que Conill ${ }^{14}$ considera uma ferramenta de apoio à avaliação de implementação e consolidação das políticas públicas.

No Brasil, o processo de municipalização das ações e serviços de saúde tem exigido, cada vez mais, o emprego de métodos analíticos e avaliativos para subsidiar gestores e técnicos na redefinição de diretrizes, estratégias e objetivos para a efetivação do atual sistema de saúde. Todavia, segundo Campos $^{15}$, os parâmetros oficialmente adotados para avaliação do desempenho dos serviços de saúde têm-se limitado a quantificar a produção das unidades, aos indicadores de produtividade e à análise das capacidades de utilização de equipamentos e instalações, sem uma aproximação significativa com o enfoque de abordagem qualitativa. 
Diante da problemática apresentada, questiona-se: as intenções da atual política de saúde destinada à mulher estão sendo realizadas na prática profissional, por meio dos processos de trabalho destinados a esse fim? Para Gonçalves ${ }^{10}$, o trabalho é uma categoria potente para responder às novas necessidades sociais que demandam mudanças. No enfoque, a transformação deve ocorrer tanto no modo de conceber o trabalho, como na maneira de processá-lo. Assim, o trabalho é uma categoria que materializa os modelos assistenciais em saúde. Por essa razão, na análise desse estudo, procurou-se identificar e compreender os diferentes elementos do processo de trabalho na assistência à saúde da mulher em situação de violência de gênero, para verificar a adequação e articulação entre o objeto, a finalidade e o instrumento de trabalho - os três elementos do processo de trabalho, segundo Marx ${ }^{16}$ - na perspectiva de um trabalho com potencial para fomentar a emancipação da mulher da opressão de gênero.

\section{Percurso metodológico}

Este estudo está vinculado ao projeto de pesquisa financiado pelo Conselho Nacional de Desenvolvimento Científico e Tecnológico - CNPq - Agência do Ministério da Ciência e Tecnologia (NCT), intitulado: $O$ trabalho das Práticas Profissionais na atenção à mulher em situação de violência doméstica e sua relação com a emancipação da opressão de gênero.

O estudo atendeu à Resolução no 196/96, hoje substituída pela 466/12, do Conselho Nacional em Saúde/Ministério da Saúde do Brasil, que dispõe e regulamenta a ética da pesquisa envolvendo seres humanos. Após aprovação do projeto de pesquisa pelo Comitê de Ética em Pesquisa do Hospital Universitário Lauro Wanderley da Universidade Federal da Paraíba, iniciou-se a investigação junto à Unidade de Saúde, cenário de estudo.

A pesquisa apresenta uma abordagem qualitativa pela necessidade de se apreender o significado cultural e ideológico que a violência de gênero assume para os profissionais de uma Equipe de Saúde da Família. Para isso, arguiu-se sobre as concepções/saberes com conteúdos da abordagem de gênero que orientam os processos de trabalho na atenção dispensada às mulheres em situação de violência.

O cenário de estudo foi uma Unidade Estratégia de Saúde da Família - ESF, localizada em João Pessoa, no estado da Paraíba, Brasil, a qual tem cadastradas cerca de novecentas famílias. A escolha desse cenário deveu-se à sua condição de mecanismo estratégico para reorientação do modelo assistencial em saúde. Disso decorre a importância de se investigarem os saberes que orientam as práticas profissionais na atenção à mulher em situação de violência doméstica na nova perspectiva paradigmática.

Os sujeitos da pesquisa foram os profissionais da ESF, local do estudo. A equipe foi composta por um médico, uma enfermeira, uma técnica de enfermagem, uma dentista, um Agente de Saúde Bucal (ASB), sete Agentes Comunitários de Saúde (ACSs) e uma marcadora de consultas. Tais profissionais foram entrevistados ao longo de um mês, a partir de um roteiro de entrevistas semiestruturado. Para garantir o sigilo e anonimato dos participantes, os depoimentos foram categorizados de acordo com a ordem do entrevistado em $E(1), E(2)$ e, assim, sucessivamente.

Como fonte do material empírico, foram usados os depoimentos dos profissionais da unidade, obtidos por meio de entrevistas, acerca de suas concepções (saberes) a respeito da violência doméstica e sobre a assistência prestada a mulheres que procuram o serviço, vítimas desse tipo de violência, no sentido de investigar a correspondência entre o discurso da política e a prática profissional que a executa, identificando os diferentes elementos do processo de trabalho.

Os depoimentos foram gravados, transcritos em sua íntegra e analisados pela técnica de análise de discurso proposta por Fiorin ${ }^{17}$. Essa técnica permitiu compreender os sentidos que as intenções da política de saúde da mulher assumem, enquanto objeto teórico-prático, a partir da identificação das contradições que produzem as tensões entre dois diferentes polos da argumentação: temas e práticas referentes à resistência à transformação do status quo - no enfoque da manutenção do modelo de atenção tradicional, em confronto com a identificação de temas e práticas, que informam possibilidades de aproximação com a transformação do modelo hegemônico. 
Nesse sentido, considerando o enfoque defendido por Gonçalves, ${ }^{10}$ em que o processo de trabalho é um dos pilares da categoria Modelos de Atenção à Saúde, os depoimentos foram analisados na perspectiva de se contrapor o modelo de atenção tradicional curativo ao novo modelo que se pretende no contexto do SUS e que, na saúde da mulher, comporta a estratégia política de emancipação de gênero. De acordo com Gonçalves ${ }^{10}$, a organização tecnológica do trabalho em saúde, ainda dominante no país nos dias atuais, atende ao modelo de atenção tradicional que recortou, como objeto de trabalho, o corpo humano em suas dimensões individual e coletiva. A finalidade, por sua vez, foi recortada como o controle das doenças e a recuperação da força de trabalho incapacitada pela doença. Entre os instrumentos, há o saber que, em combinação com a visão de mundo dos profissionais, se manifesta nos equipamentos de diagnóstico e terapêuticas.

Considerando o objeto e os objetivos deste estudo, após leituras dos textos, foram identificados os temas que orientaram a construção das seguintes categorias: 1) A invisibilidade da violência contra a mulher e sua relação com o objeto de trabalho em saúde da mulher; 2) A finalidade do trabalho em saúde da mulher: a predominância dos aspectos biológicos na busca pela cura física e psicológica dos danos; 3) Gênero: o novo saber como instrumento de trabalho na perspectiva da superação paradigmática.

\section{Resultados e discussão}

\section{A invisibilidade da violência contra a mulher e sua relação com o objeto de trabalho em saúde da mulher}

Na atenção à mulher em situação de violência doméstica, a superação da opressão de gênero há que ser considerada, enquanto objeto de trabalho, para que sejam mobilizadas estratégias capazes de nortear uma assistência especializada, associada a enfoques de outras áreas do conhecimento, como a Sociologia e o Direito, para potencializar a transformação do modelo hegemônico de saúde, de enfoque apenas biológico. Nesse contexto, defende-se a transdisciplinaridade e argumenta-se que o enfoque dos estudos e intervenções nesse campo deve remeter-se à saúde na sua concepção social, e não apenas na sua dimensão biológica, pois só assim a violência contra a mulher poderá ser vislumbrada, no interior dos serviços de saúde, como um fator que produz necessidade em saúde da mulher e que, por isso, requer a vigilância da violência de gênero, no contexto da saúde coletiva ${ }^{18}$.

Entretanto, os depoimentos dos participantes do estudo não evidenciaram essa característica, e a violência contra a mulher, além de pouco percebida, foi igualmente pouco valorizada pelos profissionais. Para Schraiber et al. ${ }^{19}$, os profissionais de saúde não reconhecem a violência contra a mulher como uma "transgressão de direito ou mesmo instaurador de um processo saúde-doença, por esse motivo desconhecem a importância de intervenção de mesmo porte socioinstitucional que as demais violências." 19 Assim, ao desconhecerem a violência doméstica e suas interfaces com a saúde, os profissionais também a desconhecem como objeto de trabalho em saúde.

O não-reconhecimento da violência nos serviços de saúde é provocado por diversos fatores, entre eles: a dificuldade, relatada pelos profissionais, de intervir em assuntos tidos como delicados e íntimos. Apesar da ampla divulgação nos meios de comunicação, com o objetivo de promover maior visibilidade ao problema e torná-lo de interesse público e civil, buscando-se romper com o caráter exclusivamente privado do fenômeno, e criar mecanismos para sua prevenção e solução, a partir da responsabilização social do problema, a intervenção pública ainda acontece de forma discreta e com pouco efeito, posto que essa problemática ainda é vista como assunto referente ao locus privado, constituindo, portanto, assunto restrito ao casal.

Essa realidade foi demonstrada nos relatos dos entrevistados, ao expressarem a sua pouca intervenção em situações que envolvem a violência perpetrada contra as mulheres, por tratar-se de um assunto íntimo e conjugal, conforme os depoimentos que afirmam: 
"É muito complicado pelo seguinte, é aquilo que a gente fala, muitas vezes perpassa pelo segredo de família". E (8)

“[...] eu disse pra ela que não queria saber o porquê nem queria entrar na vida dos dois". E (1)

Um estudo realizado por Sugg e Inuiं ${ }^{20}$, com médicos com atuação na atenção primária à saúde, buscou investigar as experiências desses profissionais no atendimento a vítimas de violência doméstica e determinar os obstáculos na identificação e intervenção nos casos. Os resultados concluíram que abordar a violência doméstica é semelhante a "abrir a caixa de Pandora", pois envolve sentimentos de incômodo e impotência, receio de ser ofensivo e interferir na vida conjugal, perda do controle da situação e constrangimento.

Para Schraiber e D'Oliveira ${ }^{21}$, os profissionais de saúde não atribuem a devida importância à violência pelo fato de as próprias mulheres, em situação de violência, não relatarem o caso. Desse modo, ele não se constitui parte da demanda do serviço. As autoras acrescentam que:

As mulheres evitam falar por medo, sentimentos de vergonha ou culpa pelo ocorrido; os familiares ou vizinhos, porque valorizam seu individualismo e não acreditam que devam se solidarizar com a mulher, ou acham que seria intromissão em assunto privado, ou ainda, também por medo; os profissionais, porque não sabem o que fazer ou não querem se adiantar à mulher ${ }^{21}$.

A consideração de impotência perante os casos de violência, seja por falta de tempo, "falta" de demanda ou por não se considerarem profissionalmente preparados, fez com que os profissionais declarassem a necessidade de capacitação em gênero para proporcionar autonomia e uma atuação mais efetiva diante de tais situações.

"Acho que a gente precisa de um curso pra gente se profissionalizar e ajudar essas pessoas de uma forma mais técnica". E (3)

A Educação Permanente em Saúde (EPS) se configura como uma estratégia de educação profissional com foco na problematização e mudanças de prática. Essa EPS, para os profissionais envolvidos com o atendimento a mulheres vitimizadas, é uma das medidas de integração e prevenção preconizadas na Lei Nacional Maria da Penha no 11.340 de agosto de 2006, criada para coibir a violência doméstica e familiar contra a mulher ${ }^{22}$. Apesar de importante, questionar e interessar-se pelo problema remetido pela mulher não é suficiente, isso porque "saber perguntar sobre as agressões é tão importante quanto saber o que fazer quando a resposta for positiva", ou seja, além de perguntar sobre a violência é importante "dar sentido assistencial a essa pergunta"19,23. Por esse motivo, treinamento, supervisão e conhecimento por parte dos profissionais, a respeito da rede de serviços existentes, são fundamentais.

Para Schraiber e D'Oliveira ${ }^{24}$, a área da saúde apresenta sérias dificuldades em trabalhar questões percebidas como culturais, sociais e até psicológicas. A proposta de investigação de casos de violência contra a mulher pode acabar por produzir duas outras situações delicadas: a primeira seria a de rejeição do problema pelo fato de ele não ser percebido como doença, mas, sim, como questão social; a segunda situação seria decorrente do efeito contrário, ou seja, por ser identificada nos serviços de saúde, a violência poderia ser percebida apenas sob o ponto de vista patológico, com o tratamento de lesões, reduzindo a questões somáticas aquilo que é fruto de relações sociais. Daí decorre a necessidade de utilização de novos saberes e técnicas que favoreçam a identificação e abordagem do problema, para contribuir com a visibilidade e enfrentamento da violência contra mulheres nos serviços de saúde. Nesse sentido, estão sendo pensadas novas formas de capacitar e abordar o problema com esses profissionais, fazendo uso de novas tecnologias, a exemplos de jogos de vídeo, com o intuito de mobilizar novos saberes que levem a mudança de práticas $^{25}$. 


\section{A finalidade do trabalho em saúde da mulher: a predominância dos aspectos biológicos na busca pela cura física e psicológica dos danos}

A finalidade do trabalho em saúde da mulher revela-se no sentido da cura e da saúde reprodutiva. Nesse sentido, os profissionais de saúde apresentam uma grande dificuldade para intervir nos casos de violência, devido ao seu caráter social. Assim, a atuação dos profissionais apresentou-se restrita ao encaminhamento, diante da ausência de agravos físicos e da doença propriamente dita.

Para Schraiber et al. ${ }^{19}$, os profissionais de saúde são, em geral, competentes para atuar com a doença e o corpo que adoece, diagnosticando e tratando casos em que há a presença de sinais e sintomas característicos. Para esses autores, ocorre a predominância de uma assistência medicalizada, tradicional e fragmentada, valorizando o modelo hegemônico biomédico e desprezando ações de caráter preventivo e de promoção à saúde. A esse respeito, Feurwerker ${ }^{26}$ afirma que as necessidades de saúde, tecnicamente definidas, e as práticas estabelecidas pelos serviços acabam por limitar a ação profissional, restringindo à atenção ao atendimento das demandas e desconsiderando as singularidades e as subjetividades que interferem no processo saúde-doença, como, por exemplo, situações e relações conjugais conflituosas. Portanto, pode-se afirmar que o contexto social dos usuários continua desvalorizado na atenção à saúde, fazendo com que a violência contra a mulher seja rejeitada nesses serviços, por não visualizarem doença ou o risco de adoecer em mulheres que procuram o serviço com tais queixas.

Nesta pesquisa, o que ilustra claramente essa situação é o processo de "psicologização" da violência. Diante da ausência de agravos físicos, os profissionais se mostram impotentes para atuarem, encaminhando aquelas usuárias a quem teoricamente tem habilidades para resolver aquele problema que, se não é físico, é mental, ou seja, aos serviços de Psicologia. Porto ${ }^{27}$ entende por "psicologização" o enfrentamento de uma questão cultural, social e/ou econômica como um transtorno psicológico. Nesse sentido, os encaminhamentos são entendidos como uma forma de transferir, para a Psicologia, um problema considerado de difícil solução ou com pouco valor para a saúde - como são percebidos os casos de violência contra a mulher -, que passa a ser demandado ao profissional da Psicologia.

Houve uma predominância quase unânime de depoimentos que ressaltavam a importância do psicólogo no serviço para tratar de tais assuntos tidos como de interesse e práticas da saúde mental, como verificou-se nos depoimentos seguintes:

"Já foi até colocado aqui, a gente ter um psicólogo, pelo menos assim, que viesse de quinze em quinze dias, entendeu? [...] Era bom que viesse um fisioterapeuta uma vez no mês, um psicólogo, principalmente". E (4)

Além de relatarem a importância e a necessidade de um psicólogo na unidade para resolver problemas que, segundo os entrevistados, são do interesse e da atuação do campo da saúde mental, os sujeitos da pesquisa também falaram a respeito do encaminhamento aos serviços de Psicologia como intervenção possível dentro das suas limitações enquanto profissional.

"Olha, primeiro eu a deixo falar, desabafar, e digo: 'olha você quer uma ajuda de um profissional, porque tem psicólogos, que procuram orientar. Se você quiser vá lá ao posto pegar um encaminhamento para o psicólogo'". E (4)

Os discursos apontaram para a utilização da Psicologia como último recurso, isso porque, para os entrevistados, dentro das possibilidades da intervenção em saúde, nada mais poderia ser feito. Sobre a psicologização da violência doméstica, tão frequente nos discursos dos entrevistados, Porto ${ }^{27}$ defende que a violência contra a mulher apresenta-se para o serviço de saúde como um problema que o modelo de atenção tradicional, biologicista e medicalizado não consegue resolver. Nesse caso, a solução para o problema é encaminhar a mulher ao serviço de Psicologia, que, segundo o autor, é visto como um serviço que "resolve coisas complicadas", "que entende de problemas da cabeça dessas mulheres problemáticas". 
Porto ${ }^{27}$ cita Schraiber e D'Oliveira ${ }^{24}$, ao afirmar que a violência contra a mulher foi, a princípio, percebida como uma doença que requeria uma intervenção baseada na racionalidade biomédica, na condição da presença de uma "base anátomo-patológica, objetiva e visível", ou seja, uma lesão física, que justificasse a intervenção, assim como acontece na justiça, em que o crime só configura-se na materialidade da prova. Nesse enfoque, a queixa de violência doméstica sem a presença da lesão visível desqualifica-se como necessidade de atenção em saúde e intervenção médica, e remete a uma intervenção social e/ou psicológica.

Tomando essa posição, os profissionais da saúde se eximem de entender o fenômeno complexo da violência contra a mulher e de reformular suas ações de forma a colaborarem no processo de prevenção e assistência a esses casos. Assim, realizam encaminhamentos automáticos que, no entender de Schraiber e D'Oliveira ${ }^{24}$, são perigosos, pois podem ser interpretados, pela mulher, como um "atestado" de que o problema é exclusivamente seu e que seu funcionamento subjetivo estaria alterado de alguma forma (doença mental).

Apesar dessa discussão sobre a participação do psicólogo no atendimento a mulheres vítimas de violência doméstica, vale salientar a importância desse profissional no apoio a mulheres e no assessoramento e orientação aos profissionais dos serviços de saúde para a promoção de uma atenção multiprofissional com caráter preventivo e de inclusão, proporcionando uma assistência efetiva e integral.

\section{Gênero: o novo saber como instrumento de trabalho na perspectiva da superação paradigmática}

O enfrentamento da violência contra a mulher no serviço de saúde requer a inclusão da perspectiva de gênero nas políticas e nas práticas profissionais ${ }^{18}$. As concepções sobre gênero e sobre violência identificadas nos depoimentos obtidos apontam que os saberes se apresentam potentes e adequados ao modelo tradicional de Saúde Pública que não considera, na assistência à saúde da mulher, a emancipação da mulher da opressão de gênero. As noções sobre as duas categorias anteriores convergem para uma perspectiva conservadora que ressalta a opressão de gênero, o que dificulta a execução de uma intervenção e de um trabalho transformador da realidade de violência vivida por mulheres no cenário investigado.

Os profissionais do serviço, ao serem questionados sobre qual a sua concepção acerca de gênero, manifestaram, frequente e prevalentemente, a falta de um entendimento coerente sobre o assunto.

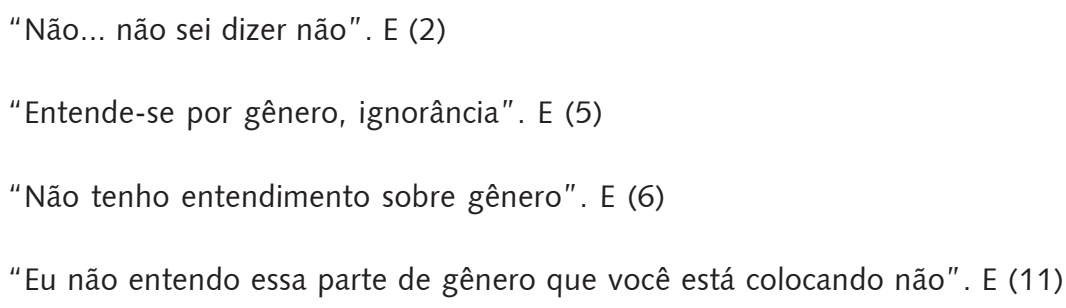

Para Schraiber e D'Oliveira ${ }^{24}$, a noção de gênero é complexa e ainda muito confundida com a ideia de sexo feminino, quando, na verdade, surgiu exatamente para ressaltar essa distinção. Ao contrário do que vem a indicar sexo, o termo gênero exprime um caráter social, material e simbólico, e não biológico. Apesar de não conceituarem e de reconhecerem a falta de entendimento sobre gênero, muitos dos depoimentos apresentam o discurso sobre a desigualdade social entre os sexos, ao fazerem referência à questão cultural e ao machismo como causa da violência, que é tida como manifestação direta do poder do homem sobre a mulher. Essas considerações evidenciam a importância de atualização sobre o tema, tendo em vista a complexidade da categoria gênero e o recente tempo em que a temática vem sendo mais amplamente discutida no setor saúde. Destarte, compreende-se que, mesmo na ausência de uma situação teórica mais aprofundada, os profissionais de saúde que apresentam uma posição ideológica sobre a igualdade entre os seres humanos são capazes de desenvolver práticas 
profissionais em uma perspectiva emancipatória, a partir das quais podem-se desenvolver novos conhecimentos sobre gênero para impactar o trabalho das práticas profissionais na saúde da mulher que sofre violência.

Os depoimentos que conduziram a identificação dessa subcategoria foram tematizados pelos profissionais na responsabilização da mulher pela violência sofrida. Os discursos indicaram uma posição social cristalizada nas relações desiguais entre os sexos, nas quais o poder masculino é aceito e naturalizado pela sociedade, e o uso da força é justificado na iminência de um rompimento dessa relação hierárquica entre os sexos para manutenção desse status quo.

"A gente sabe que tem mulheres que tiram um homem do sério com ciúme doentio". E (1)

“ [...] a mulher que está muito vulgar também, competindo com o homem. [...] Mas a mulher contribui com muita coisa. Eu acho que ela está muito visada, muito solta, competindo com o homem e homem não dá mole não. [...] Eu vejo as mocinhas gritando, botando o dedo na cara do homem e diz tanto coisa. E a violência surge daí". E (10)

Nesses depoimentos, o comportamento da mulher justifica a violência contra ela perpetrada. A reação de resistência feminina à dominação do homem é vista, nesses relatos, como o maior problema, e não a violência em si. É essa a ideia expressada no depoimento seguinte:

"[...] É a mulher que participa e que contribui para essa violência". E (5)

A esse respeito, Schraiber e D'Oliveira ${ }^{21}$ afirmam que o que ocorre é uma inversão ética reforçada moralmente, em que a "vítima", muitas vezes, é vista como pessoa indigna. Para essas mesmas autoras, as desigualdades de gênero são reforçadas politicamente, uma vez que o homem detém a autorização social para agredir sua parceira íntima, visto que lhe é sempre dado crédito de ter um bom motivo para tal, ou seja, a violência é aceita como norma de correção de um comportamento da mulher avaliado exclusivamente pelo agressor como comportamento a ser corrigido.

A responsabilização da mulher pela violência que sofre também foi colocada em pesquisa realizada por Kiss e Scharaiber ${ }^{28}$ com profissionais de saúde. Naquela pesquisa, os entrevistados afirmaram que as mulheres "são responsáveis pela situação que vivem, como resultado de suas escolhas pessoais". Segundo as autoras, os profissionais "julgam muitas vezes equivocados os valores que informam essas escolhas, imprimindo uma forte carga moral nessas posições".

Portanto, na perspectiva da superação paradigmática, esse saber que orienta o processo de trabalho se apresenta inadequado, indicando a necessidade de seu aprofundamento, sobretudo, na reorientação da formação dos profissionais de saúde no sentido de um entendimento a respeito da necessidade de se investigar e agir diante da violência de gênero.

\section{Considerações finais}

Esse estudo evidenciou resultados que se aproximaram de pesquisas semelhantes realizadas, também, com profissionais de saúde sobre suas práticas; no qual foi possível identificar a realização de práticas profissionais cujos elementos do processo de trabalho se apresentam desconexos com o que propõe a perspectiva de atenção à saúde da mulher com caráter integral e resolutivo, ou seja, um processo de trabalho, cujos elementos em articulação contemplem as diferentes dimensões da existência do sofrimento das mulheres em situação de violência.

A falta de reconhecimento da violência como um problema gerador de necessidades em saúde, ou seja, como objeto de intervenção em saúde, e a adequação da finalidade e dos saberes instrumentais ao modelo de atenção em saúde tradicional e curativo, evidenciaram um trabalho sem perspectivas de proporcionar uma assistência pautada na integralidade e com potencial para a emancipação de gênero das mulheres que sofrem esse tipo de violência e que recorrem aos cuidados daquela equipe. 
A violência contra a mulher é invisível no serviço mediante o seu caráter privado e íntimo, segundo os depoimentos obtidos. O silêncio das mulheres, o medo em intervir em assuntos conjugais, a falta de tempo e a não-identificação de danos físicos visíveis causados pela violência e que demandam cuidados em saúde são relatados como motivos que contribuem para a não-contemplação da violência doméstica no serviço de saúde. Essa não-contemplação da violência enquanto objeto de intervenção em saúde contribui significativamente para a não-adequação do segundo elemento de trabalho: a finalidade da assistência.

Diante da ausência de casos declarados na comunidade, da "baixa" incidência de casos no serviço de saúde, o que nos remete a uma possível subnotificação, e da inexistência de mulheres com queixas físicas aparentes, a violência contra a mulher acaba por não se configurar no serviço como problema que necessite de intervenção do profissional de saúde. Por esse motivo, os profissionais entendem que o melhor e mais indicado atendimento para essas mulheres seja o encaminhamento para quem, segundo eles, detém conhecimento e capacidades para intervir nesses casos: aos serviços de psicologia e saúde mental.

A psicologização da violência evidenciou, na pesquisa, a desvalorização do caráter social do processo saúde-doença, fazendo com que a violência contra a mulher seja rejeitada nesses serviços por não visualizarem a doença ou o risco de adoecer em mulheres que procuram o atendimento com tais queixas. Nesse enfoque, a finalidade nos serviços de saúde continua sendo a cura da doença instalada que, em se tratando de violência contra a mulher, se não existir danos físicos, foge das atribuições daquele profissional, relacionando o problema ao sofrimento mental, o que explica os encaminhamentos e a necessidade, expressa pelos profissionais, da presença do psicólogo na unidade para resolver tais problemas.

No que concerne ao último elemento do processo de trabalho em saúde, foi possível identificar que os saberes se apresentam potentes e adequados ao modelo tradicional de Saúde Pública que não considera, na assistência à saúde da mulher, a emancipação da mulher da opressão de gênero. As noções dos entrevistados convergiram no sentido de uma perspectiva conservadora da opressão de gênero, o que dificulta a execução de uma intervenção e de um trabalho transformador da realidade da violência vivida por mulheres no cenário investigado. A presença de discursos que veiculam a responsabilização da mulher pela violência sofrida exprime a inadequação do saber instrumental desses profissionais, o que os impede de traçar estratégias específicas no combate e prevenção desse fenômeno. Assim, falta-lhes associar a competência técnica ao caráter político e das Ciências Humanas que o setor saúde pressupõe, sobretudo depois da ampliação do conceito de saúde e da perspectiva e advento do SUS.

A violência contra a mulher precisa ser entendida no serviço como fruto de uma desigualdade de poder entre homens e mulheres, capaz de transformar a vida de suas vítimas, e, portanto, geradora de necessidades em saúde dentro do serviço, não só diante da confissão de casos ou presença de danos físicos evidentes, mas na presença de qualquer manifestação de poder e domínio do homem sobre a mulher que sugira relações violentas no interior das relações conjugais.

Prestar uma assistência integral, livre de preconceitos e estereótipos de gênero ainda é um grande desafio para os profissionais de saúde da atenção básica, fazendo-se fundamental uma reorientação das técnicas e saberes para que a violência seja reconhecida pela sua gênese social e cultural importantes. Nesse sentido, destaca-se a necessidade da qualificação das práticas profissionais por meio da educação permanente, que contemple discussões sobre conteúdos de gênero, com o objetivo de proporcionar uma reorientação do trabalho em saúde na atenção à mulher em situação de violência. O novo trabalho tomaria, por exemplo, como seu objeto: a transformação da situação de opressão para a situação de emancipação da mulher que sofre violência doméstica. Para tanto, o profissional de saúde deveria ser capaz de despertar as motivações dessas mulheres para o enfrentamento da violência, sua denúncia e as consequências dela. O recorte deste novo objeto implica a utilização de novos instrumentos de trabalho, entre os quais: a perspectiva de gênero, no que se refere ao saber sobre as relações desiguais entre os seres do sexo feminino e do sexo masculino, com a finalidade de tornar possível a resolução de conflitos entre as partes em situação de violência doméstica. 
A complexidade do trabalho em saúde no enfrentamento da violência doméstica não se encerra nos elementos do seu processo, mas requer que sejam também mobilizadas estratégias de busca, identificação e valorização dos casos de violência contra a mulher. Essa valorização deve acontecer por meio do registro e da notificação dos casos, além de um encaminhamento com possibilidades de resolubilidade. Trabalho esse que só será possível através de uma equipe integrada e motivada e com a disposição de uma rede de serviços que se articule e se comunique, para que o profissional sinta-se seguro em dar seguimento à sua atuação.

O enfrentamento da violência de gênero, no interior dos serviços, requer também: o desenvolvimento de um de trabalho que valorize o processo saúde-doença na sua interface social, privilegiando não apenas a dimensão biológica do adoecimento e a medicalização, mas o contexto de vida das mulheres em situação de violência; o estabelecimento de relações interpessoais fortes entre profissional e usuária, com o estreitamento de vínculos e o reconhecimento da escuta e da orientação como equipamentos dos cuidados em saúde. Nesse contexto, pode-se promover uma assistência com potencial emancipatório da opressão de gênero que tenha, entre suas finalidades, a luta contra a passividade e as dependências, pelo empoderamento de mulheres que buscam os cuidados daqueles profissionais.

\section{Colaboradores}

As autoras Luana Rodrigues de Almeida e Ana Tereza Medeiros Cavalcanti da Silva participaram, igualmente, da elaboração do artigo, da análise do material empírico, da sua discussão, redação e da revisão do texto. A autora Liliane dos Santos Machado participou da revisão bibliográfica, da discussão, redação e revisão do texto. 
O OBJETO, A FINALIDADE E OS INSTRUMENTOS DO PROCESSO ...

\section{Referências}

1. Organización Panamericana de la Salud. Resolución XIX: Violencia y Salud. Washington, DC: Opas; 1993.

2. Krug EG, Dahlberg LL, Mercy JA, Zwi AB, Lozano R. Relatório mundial sobre violência e saúde. Genebra: Organização Mundial de Saúde; 2002.

3. Almeida LR, Silva ATMC, Silva CC, Souza JA, Lucena, KDT. A violência de gênero na concepção dos profissionais de saúde da Atenção Básica. Saude Debate. 2011; 35(90):396-404.

4. Borrell C, Artazcoz L. La relación entre el sexismo percibido y la depressión. Saude Debate. 2009; 33(82):316-25.

5. Fonseca RMGS. Equidade de gênero e saúde das mulheres. Rev Esc Enferm USP. 2005; 39(4):450-9.

6. Scott J. Gênero: uma categoria útil para análise histórica. Recife: SOS Corpo; 1991.

7. Saffioti H. Gênero, patriarcado e violência. São Paulo: Fundação Perseu Abramo; 2011.

8. Guedes RN, Silva ATMC, Fonseca RMGS. A violência de gênero e o processo saúde-doença das mulheres. Esc Anna Nery. 2009; 13(3):625-31.

9. Chauí M. Cultura e democracia: o discurso competente e outras falas. 11a ed. São Paulo: Moderna; 2006.

10. Gonçalves RBM. Práticas de saúde: processos de trabalho e necessidades. São Paulo: Departamento de Medicina Preventiva da Faculdade de Medicina da USP; 1992.

11. Ministério da Saúde. Secretaria de Atenção a Saúde. Departamento de Ações Programáticas Estratégicas. Política Nacional de Atenção Integral à Saúde da Mulher: princípios e diretrizes. Brasília, DF: SAS; 2004.

12. Souza JA, Silva ATMC. O significado do impacto da violência doméstica na saúde mental de mulheres no estado da Paraíba. In: Anais do Encontro de Iniciação Científica; 2008- 2010; João Pessoa. João Pessoa: Editora Universitária/UFPB; 2008-2010. [1 cd rom].

13. Presidência da República. Secretaria Especial de Políticas para Mulheres. Pacto Nacional de Enfrentamento à violência contra Mulher. Brasília, DF: SEPM; 2007.

14. Conill EM. Notas sobre cuidados no monitoramento de políticas e programas intersetoriais. Cienc Saude Colet. 2007; 12(6):1422-8.

15. Campos GWS. Saúde pública e saúde coletiva: campo e núcleo de saberes e práticas. Cienc Saude Colet. 2000; 5(2):219-30.

16. Marx K. O capital. Rio de Janeiro: Brasiliense; 1996.

17. Fiorin JL. Linguagem e ideologia. 6a ed. São Paulo: Ática; 2007.

18. Guedes RN, Fonseca, RMGS. A autonomia como necessidade estruturante para o enfrentamento da violência de gênero. Rev Esc Enferm USP. 2011; 45(2):1731-5.

19. Schraiber LB, D'Oliveira AFPL, Falcão MTC, Figueiredo WS. Violência dói e não é direito: a violência contra a mulher, a saúde e os direitos humanos. São Paulo: Ed. Unesp; 2005.

20. Sugg NK, Inui T. Primary care physicians' response to domestic violence. JAMA. 1992; 267(27):3157-60.

21. Schraiber LB, D'Oliveira AFPL. Romper com a violência contra a mulher: como lidar desde a perspectiva do campo da saúde. Athenea. 2008; 14:229-36. 
22. Lei no 11340, "Lei Maria da Penha", de 22 de setembro de 2006. Cria mecanismos para coibir a violência doméstica e familiar contra a mulher. Diário Oficial da República Federativa do Brasil. 2006 Set 22.

23. Schraiber LB. Violência contra as mulheres e políticas de saúde no Brasil: o que podem fazer os serviços de saúde? Rev USP. 2001; (51):104-13.

24. Schraiber LB, D'Oliveira AFPL. Violência contra as mulheres: interfaces com a saúde. Interface (Botucatu). 1999; 3(5):11-26.

25. Almeida LR, Silva ATMC, Machado, LS. Serious games para capacitação de profissionais de saúde na atenção à violência de gênero. Rev Bras Educ Med. 2013; $37(1): 110-9$

26. Feuerwerker LM. Modelos tecnoassistenciais, gestão e organização do trabalho em saúde: nada é indiferente no processo de luta para a consolidação do SUS. Interface (Botucatu). 2005; 9(18):489-506

27. Porto $M$. Violência contra a mulher e atendimento psicológico: o que pensam os/as gestores/as municipais do SUS. Psicol Cienc Prof. 2006; 26(3):426-39.

28. Kiss LB, Schraiber LB. Temas médico-sociais e a intervenção em saúde: a violência contra mulheres no discurso dos profissionais. Cienc Saude Colet. 2011; 16(3):1943-52.

Almeida LR, Silva ATMC, Machado LS. El objeto, la finalidad y los instrumentos del proceso de trabajo en salud en la atención a la violencia de género en un servicio de atención básica. Interface (Botucatu). 2014; 18(48):47-59.

El objetivo de este estudio fue analizar las prácticas profesionales de la atención a la salud de la mujer en situación de violencia, identificando los elementos del proceso de trabajo y su relación con la emancipación de la opresión de género. Para ello, se investigó con profesionales de la salud de un servicio de atención primaria si las intenciones de la actual política de salud de la mujer se estarían realizando en la práctica profesional por medio de los procesos de trabajo destinados a esa finalidad. Por medio de la investigación cualitativa, los resultados mostraron la indivisibilidad de la violencia en el servicio y el desconocimiento de la categoría Género y de su complejidad. Por lo tanto, se configura la adecuación del proceso de trabajo en salud en la atención a mujeres en situación de violencia como un gran desafío para la producción de una asistencia potencialmente emancipadora de la opresión de género y de acuerdo con los presupuestos de la política.

Palabras clave: Violencia contra la mujer. Proceso de trabajo. Profesionales de Salud. 
